\title{
PROPOSING A CENTRAL AEC ONTOLOGY THAT ALLOWS FOR DOMAIN SPECIFIC EXTENSIONS
}

\author{
Mads Holten Rasmussen ${ }^{1}$, Pieter Pauwels ${ }^{2}$, Christian Anker Hviid ${ }^{3}$ and Jan Karlshøj ${ }^{4}$
}

\begin{abstract}
In the last years, several ontologies focused on structuring domain specific information within the scope of Architecture, Engineering and Construction (AEC) have emerged. Several of these individual ontologies redefine core concepts of a building already specified in the publicly available ontology version of the ISO standardised Industry Foundation Classes (IFC) schema, thereby violating the W3C best practice rule of minimum redundancy. The voluminous IFC schema with origins in a closed world assumption is likewise violating this rule by redefining concepts about time, location, units etc. already available from other sources, and it is furthermore violating the rule of keeping ontologies simple for easy maintenance. Based on all the available ontologies, we propose a simple Building Topology Ontology (BOT) only covering the core concepts of a building, and three methods for extending this with domain specific ontologies. This approach makes it (1) possible to work with a limited set of core building classes, and (2) extend those as needed towards specific domain ontologies that are in hands of business professionals or domain-specific standardisation bodies, such as the European Telecommunications Standards Institute (ETSI), buildingSMART, the Open Geospatial Consortium (OGC), and so forth.
\end{abstract}

Keywords: Linked Data, Building Information Modelling, Web of Data, Building Topology Ontology.

\section{INTRODUCTION}

Design and planning of buildings is a complex and iterative process involving interaction between several stakeholders. A substantial part of the complexity originates from the amount of information to be handled, the number of parties possessing and consuming the information, and the lack of tools that can combine the distributed information, structure the data and present it in a way that is beneficial to the individual building planner (Kiviniemi, 2005). Building Information Modelling (BIM) has been introduced in the industry to overcome this problem. With this introduction, the entire industry is now shifting from an initial BIM stage with single-disciplinary silo models (maturity level 1), to a data-centric BIM stage (maturity level 3) with a purposefully interlinked network of data (Succar, 2009).

1 PhD student, Department of Civil Engineering, Technical University of Denmark (DTU), Lyngby, DK, mhoras@byg.dtu.dk

2 Assistant Professor, Department of Architecture and Urban Planning, Ghent University, BE pipauwel.Pauwels@UGent.be

3 Assistant Professor, Department of Civil Engineering, Technical University of Denmark (DTU), Lyngby, DK cah@byg.dtu.dk

4 Associate Professor, Head of Section, Department of Civil Engineering, Technical University of Denmark (DTU), Lyngby, DK jak@byg.dtu.dk 
Linked Data technologies allow for this shareable data model to be not one model, but several smaller interlinked models together forming a complete data representation. The partitioning into sub-disciplinary data models solves the issue with several stakeholders needing to specify capabilities of a single building object. It makes it furthermore easier to specify and respect legal responsibilities and intellectual property rights (IPR). Another advantage of linked data is that a vast amount of data is already available online, making it possible to integrate the building models with linked open data such as weather information, physical capabilities of materials, product datasheets, sensor readings, unit conversion and Geographic Information System (GIS).

This paper is situated in this context of interlinking building data using web technologies. Several ontologies have now been specified and proposed, aiming to capture specific knowledge related to buildings (geographical location, sensor data, domotics, construction data, and so forth). The aim of this paper is to review these publicly available ontologies and to clarify how they overlap each other (section 2). In section 3 a simple BOT ontology is suggested, to represent the overlapping building data found in section 2, and in section 4, three different approaches to extending BOT by existing ontologies (GIS and appliances in this article), by linking datasets (each following an ontology) are examined, hence clearly showing how data and ontology reuse can be done for the AEC industry. The approaches are (1) through an upper ontology (2) by defining equivalence classes and (3) by using typed links, and the latter comes out as the preferred approach.

\section{REVIEW OF EXISTING BUILDING ONTOLOGIES}

Recent research projects suggest using web of data technologies for managing building data, thereby making it possible to link interconnected information between disciplines in the AEC domain. Figure 1 shows examples of AEC-datasets that have interdependencies with other AEC-datasets. Common for them is that they all consume data about the single components of the building in scope. W3C Best Practices for data on the web (Lóscio et al., 2016) states that in order to increase interoperability and reduce redundancies, reuse of vocabularies should be attempted, but in research projects the same concepts of a building are contradictory redefined repeatedly.

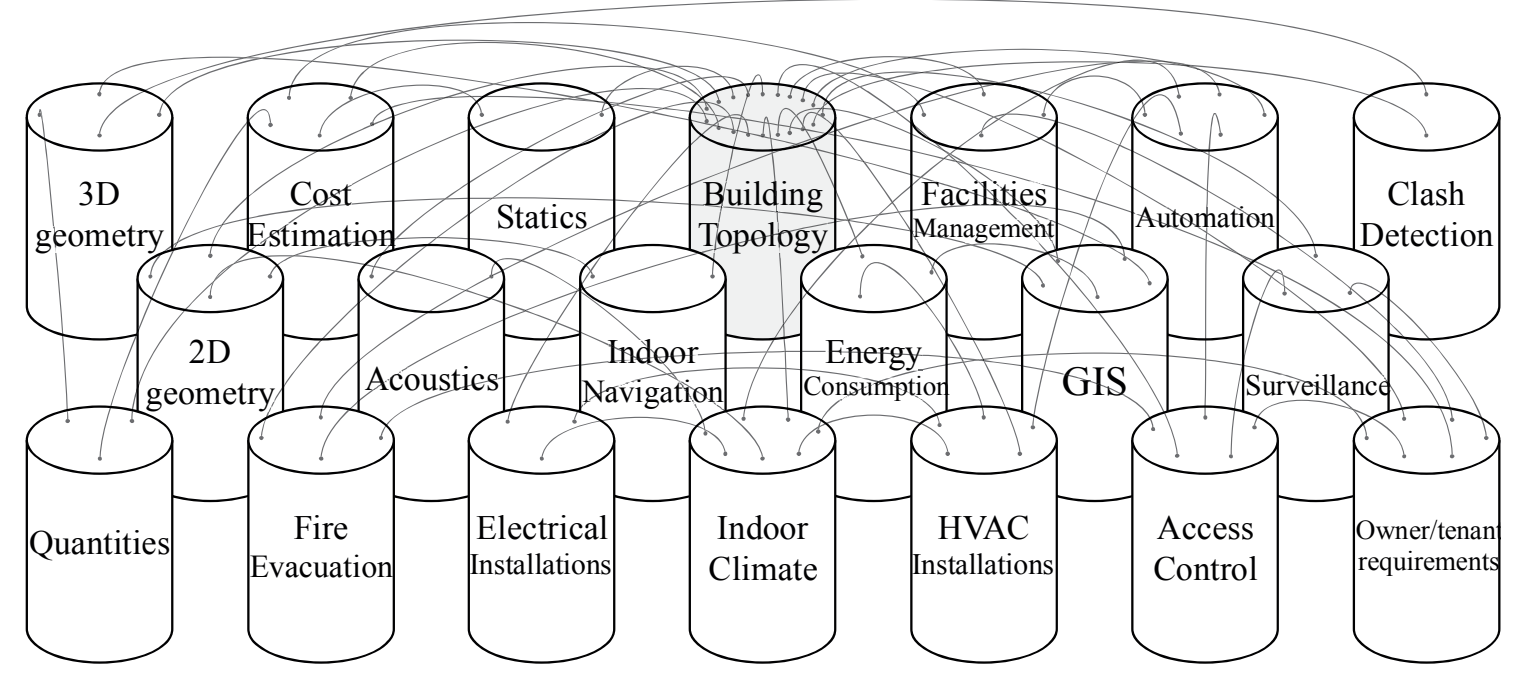

Figure 1: Example of interdependencies between datasets. 
In this section a selection of ontologies are examined, specifically aiming to retrieve concepts and classes about buildings. We distinguish between generic ontologies (broad scope) and domain-specific ontologies (narrow scope). The considered ontologies are listed in Table 1 where it is also stated which domain they seek to cover, whether they are accessible online and the name of the building related classes if these are part of the ontology. The offline ontologies are mentioned in the literature, but as they are not publicly available, they are of very limited use in a linked data environment.

\subsection{Generic ontologies}

Generic ontologies encompass a wide span of concepts to represent knowledge about the world as we know it. One of the largest knowledge bases on the web of data is DBpedia which is a community effort to extract structured information from Wikipedia and make it available on the web (Auer et al., 2007). The DBpedia ontology contains classes to describe a place and a building, but the main purpose of the schema is to define simple facts such as floor area, building type and number of floors, and hence no further details of the building components and their relationships and context to the building can be described. The same accounts for schema.org, a joint effort between Bing, Google and Yahoo (Ronallo, 2012), which can only hold information about where a building is located and mainly sees it as a location of a certain service of importance to people. Another widely used example is the Suggested Upper Merged Ontology (SUMO), a socalled upper ontology or superstructure for information that is true in lots of domains (Pease, no date). Concepts already defined in SUMO have been diligently used in some of the domain ontologies described in section 2.2.

The most general schema for describing buildings is IFC (Liebich and Wix, 1999). Several research projects have dealt with the conversion of this schema into an ontology. Pauwels and Terkaj (2016) suggested the if $O W L$, and T. M. De Farias, Roxin and Nicolle (2015) suggested the if $W O D$, which further simplifies querying. The if $c O W L$ ontology contains 1313 classes and 1580 object properties and besides from defining information about a building, it can also hold data related to time planning, costs, physical units, etc. An ongoing initiative aims at extending the schema to also hold information about roads (Lee and Kim, 2011) and bridges (Yabuki et al., 2006). For the purpose of a simple building representation one may argue that the IFC schema is too extensive, and for the same reason (Pauwels and Roxin, 2016) suggested SimpleBIM, which cuts away elements like geometric data and intermediate relation instances between objects. SimpleBIM is not an individual ontology, but rather an approach to post-process an ifc $O W L$-compliant RDF graph with a simplified building representation.

A core ontology initiated by the Dutch civil engineering industry called Cbim consists of a minimal schema containing class definitions for objects, their properties and their relations (van Nederveen, Beheshti and Willems, 2010). The ontology functions as an upper ontology with the capability of checking that relationship constraints are not violated, and the minimal extent of it means that it should be extended depending on demand. Another general building ontology is the BIM Shared Ontology (BIMSO), which can likewise serve as a core for domain specific ontologies. It uses the UNIFORMAT II classification system for declaring the classes and is therefore not a minimal schema as Cbim, but rather an alternative to IFC (Karshenas and Niknam, 2013). 


\subsection{Domain-specific ontologies}

Domain-specific ontologies limit to very specific domains, in contrast to the earlier mentioned generic ontologies. In a sense, building ontologies such as ifc OWL, BIMSO, and Cbim could be considered ontologies specific to the building domain as well, but they cover a wider domain as they point to ontologies outside the building domain as well (units, geometry, location, etc.). This also happens with, for example, Geographical Information Systems (GIS) and smart cities ontologies, which typically have a geographical basis that heavily points to buildings. cityGML, DAREED and SEMANCO are examples of ontologies in the smart city domain that include the concept of a building. cityGML and SEMANCO are the only ones that were available online at the time of writing. cityGML has its own definition of a building. SEMANCO includes $S U M O$ for describing overall concepts like Building and Floor but defines its own classes for what is not contained in SUMO (Madrazo, Sicilia and Gamboa, 2012).

Table 1: Building topology information in domain specific ontologies.

\begin{tabular}{|c|c|c|c|c|c|c|}
\hline Ontology & Domain & Online & Building & Storey & Room & Elements \\
\hline DBpedia & World & $X$ & Building & - & - & - \\
\hline Schema.org & World & $\mathrm{X}$ & $\begin{array}{l}\text { Civic- } \\
\text { Structure }\end{array}$ & - & - & - \\
\hline ifcOWL & AEC & $X$ & IfcBuilding & $\begin{array}{l}\text { IfcBuildingS } \\
\text { torey }\end{array}$ & IfcSpace & IfcElement \\
\hline ifcWOD & AEC & - & $X$ & $\mathrm{X}$ & $X$ & $X$ \\
\hline BIMSO & AEC & - & $?$ & $?$ & $?$ & $?$ \\
\hline CBIM & AEC & $X$ & - & - & - & Object \\
\hline SEMANCO & $\begin{array}{l}\text { Smart } \\
\text { cities }\end{array}$ & $\mathrm{X}$ & $\begin{array}{l}\text { SUMO: } \\
\text { Building }\end{array}$ & $\begin{array}{l}\text { SUMO: } \\
\text { Floor }\end{array}$ & Space & subclasses \\
\hline cityGML & $\begin{array}{c}\text { Smart } \\
\text { cities }\end{array}$ & $\mathrm{X}$ & Building & - & - & - \\
\hline DAREED & $\begin{array}{c}\text { Smart } \\
\text { cities }\end{array}$ & - & $?$ & $?$ & $?$ & $?$ \\
\hline SEAS & Systems & $\mathrm{X}$ & Building & $\begin{array}{l}\text { Building- } \\
\text { Storey }\end{array}$ & Room & $\begin{array}{l}\text { Building- } \\
\text { Space- } \\
\text { Connection }\end{array}$ \\
\hline SAREF & $\begin{array}{l}\text { Smart } \\
\text { homes }\end{array}$ & $\mathrm{X}$ & - & - & $\begin{array}{l}\text { Building- } \\
\text { Space }\end{array}$ & $\begin{array}{l}\text { Building- } \\
\text { Object }\end{array}$ \\
\hline DogOnt & $\begin{array}{l}\text { Smart } \\
\text { homes }\end{array}$ & $\mathrm{X}$ & Building & Storey & Room & $\begin{array}{l}\text { Building- } \\
\text { Thing }\end{array}$ \\
\hline ThinkHome & $\begin{array}{l}\text { Smart } \\
\text { homes }\end{array}$ & $\mathrm{X}$ & Building & $\begin{array}{l}\text { Building- } \\
\text { Storey }\end{array}$ & Space & $\begin{array}{l}\text { Opening, } \\
\text { Equipment }\end{array}$ \\
\hline
\end{tabular}

With the prevalence of Internet of Things (IoT) technologies, sensors, actuators, meters and home appliances need a common way of communicating with a building to create 
so-called Smart Homes. Smart Appliances REFerence (SAREF) is an example of an ontology in this domain which includes the definition of a building (Daniele, 2015). DogOnt is also concerned with home automation, and it defines both controllable and architectural building elements as well as building spaces (Corno and Bonino, 2008). Another ontology, ThinkHome, which consists of several smaller domain-specific ontologies, that together shape the Smart Home Ontology, is a refinement of the DogOnt ontology, extending it with representations for energy information (Kofler, Reinisch and Kastner, 2012). Part of ThinkHome is the Architecture and Building Physics Information ontology, which represents building information for the scope of Smart Home Systems. It retrieves its classes from gbXML - an XML schema for representing buildings for indoor climate and energy simulations. OntoFM is an ontology for sensor-based building monitoring relying on the IFC specification for representing the building, but also inheriting key concepts from $S U M O$ (Dibley et al., 2012).

Smart Energy Aware Systems (SEAS) consists of several smaller ontologies together forming a whole infrastructure for storing data about systems that consume energy. Part of this infrastructure is the Building ontology, which defines spatial elements of a building, but only the building elements which act as a connection between building spaces. The device ontology further defines controllable devices and sensors. The ontology uses terms defined in if $O W L, g b X M L$ and $S A R E F$, but does not extend these ontologies as they are only referred to by $r d f_{s}:$ see $A l s o$.

\section{Building Topology OnTOLOGY (BOT)}

From Section 2, it can be concluded that several ontologies violate the principle of reuse, which might be due to the fact that several ontologies cover the whole AEC domain. Another W3C principle is to keep schemas light for easy reuse. This might be a second key reason why so little ontology reuse is present in the AEC domain. Although a domain-specific and standardised building ontology is available (ifc $O W L$ ), it is far from simple / reusable. Therefore, we suggest creating a simple Building Topology Ontology for easy reuse across the considered domain ontologies. This ontology is made available at (Rasmussen, 2016), and it is a simple ontology only defining the core topology of a building should include the physical and conceptual objects and their relationships. This can be limited to the following concepts:

- A building is subdivided into storeys and spaces

- A space can be bounded by building elements

- A space can contain building elements

According to these definitions, there is a direct relationship between a space and its adjacent or contained building elements, but relationships to the storey and the building can be inferred by an owl:propertyChainAxiom. The following First Order Logic (FOL) rules or subsets of these can infer has element-relationships:

$$
\begin{gathered}
\forall \mathrm{b}, \mathrm{s}, \mathrm{r}, \mathrm{e}: \text { hasStorey }(\mathrm{b}, \mathrm{s}) \wedge \text { hasSpace }(\mathrm{s}, \mathrm{r}) \wedge \text { adjacentElement }(\mathrm{r}, \mathrm{e}) \rightarrow \text { hasElement }(\mathrm{b}, \mathrm{e}) \\
\text { where } \mathrm{b}=\text { Building, } \mathrm{s}=\text { Storey, } \mathrm{r}=\text { Space, e=Element }
\end{gathered}
$$


Limiting the ontology to 4 key classes and 5 object properties, results in a very simple ontology that can easily be extended by anyone (see Figure 2). Even the ontologies listed in Table 1 are compatible with this ontology, so also they can reuse these key concepts. Such ontology reuse can appropriately stimulate a networked data exchange as explained in the introduction of this paper.

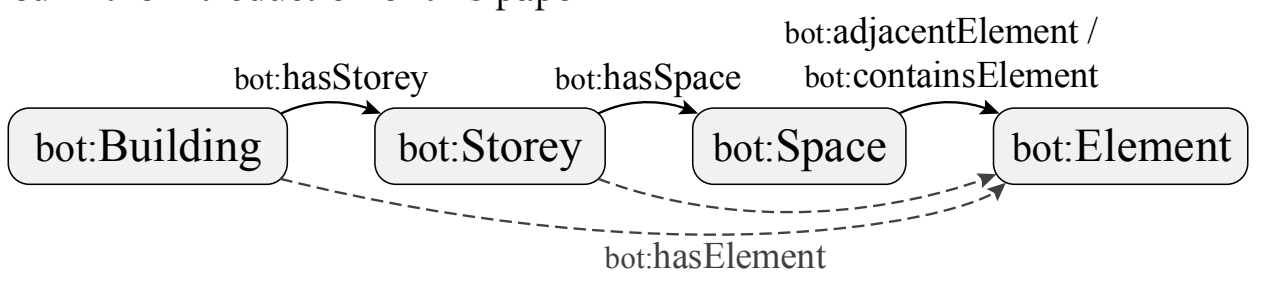

Figure 2: Simple Building Topology Ontology (BOT)

\section{LINKING ONTOLOGIES}

Several strategies exist for linking separate datasets that represent distinct ontologies. As we now have a situation with a central BOT ontology that is to be reused by several of the ontologies from section 2, we need to be specific in how this reuse should ideally take place. Overall, three approaches can be specified for linking data from different ontologies. These approaches are all visualised in the example shown in Figure 3, where a BOT-compliant dataset is extended with geographical and appliance data. The same approaches can be used for further extension with $S A R E F$, DogOnt etc.

The ontology layer, also called the terminological component (TBox) is above the dashed line and the data layer also called the assertion component (ABox) is below.

To the left in Figure 3 the separate ontology abbreviated by a $h$ for heater ontology has a class h:Heater, which is specified as a subclass of bot:Element. Thereby it inherits the properties of its superclass; in this case the OWL property chain rule defining that the heater is related to the building in which it belongs, given that it is contained in a space of that building (not shown in the figure). This automatically infers the bot:hasElement link from the building. When linking to an upper ontology this approach is used.

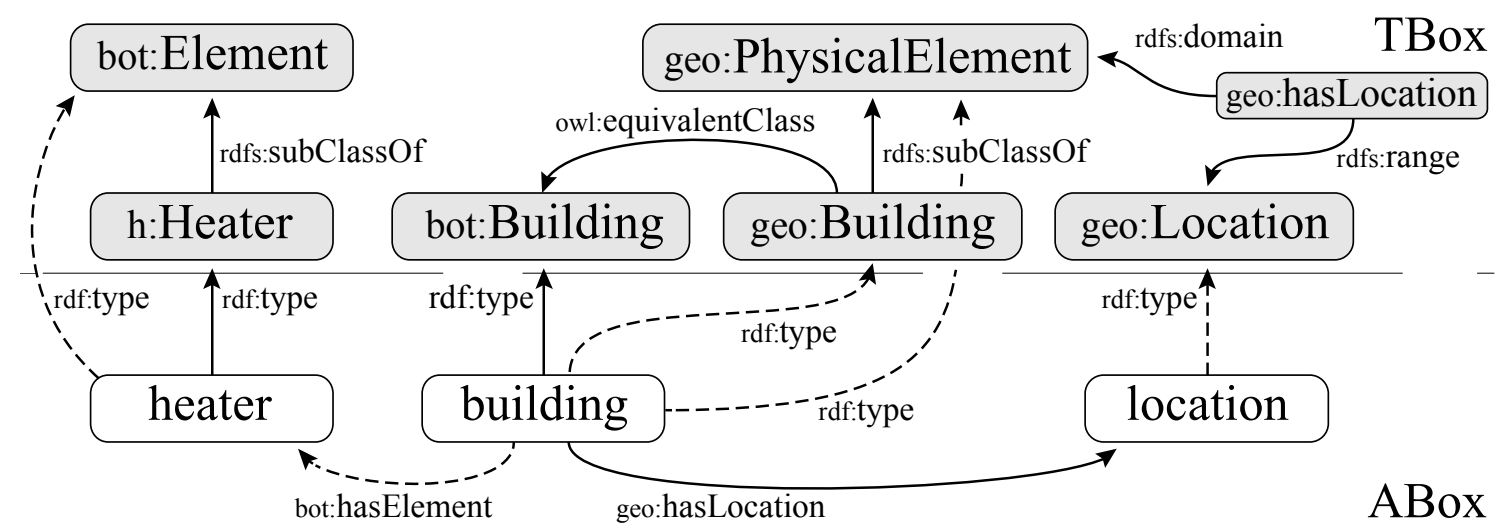

Figure 3: Extending a BOT-compliant dataset with geographical and appliance data.

owl:equivalentClass in the middle of Figure 3 specifies that a class defined in one ontology has an equivalent class in another ontology. The geo:Building class of the geography ontology is specified to be equal to the bot:Building class. This statement is 
defined in the TBox, hence extending the BOT ontology, and it infers the fact that the building instance is of type geo:Building and its superclass geo:PhysicalElement.

Establishing typed links between individuals in the data layer is another approach to combining ontologies. If the GEO ontology specifies the domain and range of the geo:hasLocation property as illustrated, it is inferred that the building instance is a geo:PhysicalElement and the location instance is a geo:Location. The redundant geo:Building class is unnecessary with this approach. One advantage of the typed links approach is that the links are visible at the data layer, giving a better transparency to what is defined.

\section{CONCLUSION}

By examining domain specific ontologies in the scope of AEC it was found that they all redefine similar concepts of a building, hence creating overlaps. The suggested simple extendable BOT ontology will help overcome the observed redundancy issues currently violating $\mathrm{W} 3 \mathrm{C}$ best practice rules, and it will allow for an easily accessible, extendable base to connect with existing and future domain ontologies, hopefully leading to a wider distribution and a more rapid development of the technology.

Distributed ontologies have several advantages over a one-size fits all, as it makes it possible for domain specialists to develop and maintain ontologies meeting the specific demands, and use of web technologies in addition makes it possible for experts in other industries to have a better interface to the AEC industry. In section 2 specific domain ontologies were investigated, but it would not be hard to imagine new ones in other domains emerging in near future.

Three different approaches to linking ontologies were explained. When extending an existing ontology with new classes, defining them as subclasses of a more general class is applicable as it allows for inheritance of properties. The suggested BOT ontology might benefit from having more specific classes for building related elements in the future as the bot:Element class is tending toward an upper ontology definition, which was not the intention. A starting point could be to define subclasses defined in IFC, and for further detailing more subclasses of bot:Element could be generated in domain ontologies. Establishing typed links was found to be the better linking approach as it provides transparency and omits the redundancy of ie. owl:equivalentClass. It also allows for a direct link between for example sensor data and a bot:Space instance, which can easily be defined by the end user.

\section{ACKNOWLEDGMENTS}

Special thanks to the Alectia-Foundation and Innovation Fund Denmark for funding.

\section{REFERENCES}

Auer, S., Bizer, C., Kobilarov, G., Lehmann, J., Cyganiak, R. and Ives, Z. (2007) 'DBpedia: A Nucleus for a Web of Open Data', in The semantic web. Springer, pp. 722-735. Available at: http://www.cis.upenn.edu/ zives/research/dbpedia.pdf.

Corno, F. and Bonino, D. (2008) 'DogOnt - Ontology Modeling for Intelligent Domotic Environments', in ISWC '08 - Proceedings of the 7th International Conference on The Semantic Web, pp. 790-803. doi: 10.1007/978-3-540-88564-1_51. 
Daniele, L. (2015) SAREF: the Smart Appliances REFerence ontology. Available at: http://ontology.tno.nl/saref/ (Accessed: 24 November 2016).

Dibley, M., Li, H., Rezgui, Y. and Miles, J. (2012) 'An ontology framework for intelligent sensor-based building monitoring', Automation in Construction. Elsevier B.V., 28, pp. 1-14. doi: 10.1016/j.autcon.2012.05.018.

Farias, T. M. De, Roxin, A.-M. and Nicolle, C. (2015) 'IfcWoD, Semantically Adapting IFC Model Relations into OWL Properties', in Proceedings of the 32nd CIB W78 Conference. Eindhoven, pp. 175-185.

Karshenas, S. and Niknam, M. (2013) 'Ontology-Based Building Information Modeling', Computing in Civil Engineering, pp. 476-483. doi: http://dx.doi.org/10.1061/9780784413029.060.

Kiviniemi, A. (2005) Requirements management interface to building product models, VTT Publications. Stanford University.

Kofler, M. J., Reinisch, C. and Kastner, W. (2012) 'A semantic representation of energyrelated information in future smart homes', Energy and Buildings. Elsevier B.V., 47, pp. 169-179. doi: 10.1016/j.enbuild.2011.11.044.

Lee, S. H. and Kim, B. G. (2011) 'IFC extension for road structures and digital modeling', Procedia Engineering. Elsevier B.V., 14, pp. 1037-1042. doi: 10.1016/j.proeng.2011.07.130.

Liebich, T. and Wix, J. (1999) 'Highlights of the development process of industry foundation classes', in Proceedings of the 1999 CIB W78 Conference.

Lóscio, B. F., Burle, C., Calegari, N., Greiner, A., Isaac, A., Iglesias, C. and Laufer, C. (2016) Data on the Web Best Practices, W3C. Available at: http://www.w3.org/TR/dwbp/ (Accessed: 8 November 2016).

Madrazo, L., Sicilia, A. and Gamboa, G. (2012) 'SEMANCO: Semantic Tools for Carbon Reduction in Urban Planning', in Proceedings of the 9th European Conference on Product and Process Modelling.

Nederveen, S., Beheshti, R. and Willems, P. (2010) 'Building Information Modelling in the Netherlands: A Status Report', in W078-Special Track 18th CIB World Building Congress. Salford, United Kingdom, pp. 28-40.

Pauwels, P. and Roxin, A. (2016) 'SimpleBIM: From full ifcOWL graphs to simplified building graphs', in ECPPM2016.

Pauwels, P. and Terkaj, W. (2016) 'EXPRESS to OWL for construction industry: Towards a recommendable and usable ifcOWL ontology', Automation in Construction. Elsevier B.V., 63, pp. 100-133. doi: 10.1016/j.autcon.2015.12.003.

Pease, A. (no date) Suggested Upper Merged Ontology (SUMO). Available at: http://www.ontologyportal.org.

Rasmussen, M. H. (2016) BOT: Building Topology Ontology. Available at: www.student.dtu.dk/ mhoras/bot (Accessed: 6 December 2016).

Ronallo, J. (2012) 'HTML5 Microdata and Schema.org', Code4Lib Journal, 16. Available at: https://scholar.google.dk/scholar?hl=da\&q=schema.org\&btnG=.

Succar, B. (2009) 'Building information modelling framework: A research and delivery foundation for industry stakeholders', Automation in Construction. Elsevier B.V., 18(3), pp. 357-375. doi: 10.1016/j.autcon.2008.10.003.

Yabuki, N., Lebegue, E., Gual, J., Shitani, T. and Zhantao, L. (2006) 'International Collaboration for Developing the Bridge Product Model "IFC-Bridge”, in Proceedings of the 2006 Joint International Conference on Computing and Decision Making in Civil and Building Engineering. Montréal, Canada, pp. 1927-1936. 